\title{
O TRABALHO DE ENFERMAGEM EM ATENÇÃO PRIMÁRIA À SAÚDE - A ASSISTÊNCIAÀ SAÚDE DA FAMÍLIA ${ }^{1}$
}

\author{
THE NURSING WORK IN PRIMARY ATTENTION TO HEALTH - THE FAMILY \\ HEALTH ASSISTANCE \\ EL TRABAJO DE ENFERMERIA EN LA ATENCIÓN PRIMARIA A LA SALUD \\ - LA ASISTENCIA A LA SALUD DE LA FAMILIA
}

Rafaela Azenha Teixeira ${ }^{2}$

Silvana Martins Mishima ${ }^{3}$

Maria José Bistafa Pereira

\begin{abstract}
RESUMO: Este estudo insere-se no projeto integrado de pesquisa A organização do trabalho em atenção primária à saúde - uma perspectiva para o trabalho de enfermagem. Tem como objetivo estudar a percepção dos trabalhadores de enfermagem quanto à configuração da prática de enfermagem em atenção primária à saúde na perspectiva de atenção à saúde das famílias. A investigação configura-se como um estudo de caso, tomando por foco os trabalhadores que atuam no Programa de Saúde da Familia no município de Batatais, sendo realizada entrevista semiestruturada com os trabalhadores de enfermagem da equipe do PSF. Foi realizada a análise temática do conjunto dos dados, sendo a categorização inicial efetivada com o auxílio do software ETHNOGRAPH. Os temas identificados na fala dos trabalhadores referem-se à: integralidade, cuidar da saúde, ir em busca do usuário e vínculo. Estes temas encaminham para uma percepção acerca do trabalho no PSF como cheio de dificuldades mas que conduz para uma prática voltada para a efetivaçăo da integralidade da assistência e de maior compartilhar das decisőes com a clientela.
\end{abstract}

PALAVRAS-CHAVE: Atenção Primária à Saúde, trabalho de enfermagem, saúde da familia

\section{INTRODUÇĀO}

O estudo ora proposto insere-se no projeto integrado de pesquisa "A organização do trabalho em atenção primária à saúde - uma perspectiva para o trabalho de enfermagem", cujo objetivo central é analisar o trabalho de enfermagem na organização dos serviços de atenção primária dentro do processo mais recente de municipalização do setor saúde, e aí localizando mais centralmente a assistência à saúde da familia.

A preocupação com a assistência à familia não é recente, e pode-se verificar que de cerca de 40 anos para cá, o interesse pelo estudo da família tem crescido em todos os setores de conhecimento, cada ramo científico abordando-a por um ângulo específico.

Em 1948, com o surgimento do Sistema de Saúde na Inglaterra, em certa medida retomase a concepção do médico de família, mas o foco de seu trabalho é estritamente clínico limitado à relação médico/paciente.

Segundo Dominguez (1998), mais contemporaneamente, novas concepções têm surgido,

\footnotetext{
1 Trabalho financiado pelo CNPq.

${ }^{2}$ Enfermeira e pós graduanda - nivel mestrado em Enfermagem em Saúde Pública do Depto. Materno Infantil e Saúde Pública - EERP- USP.

${ }^{3}$ Profa. Dra. do Depto Materno Infantil e Saúde Pública - EERP-USP.

${ }^{4}$ Profa. Assistente do Depto Materno Infantil e Saúde Pública - EERP-USP.
} 
principalmente a partir de Alma Ata - Conferência de Cuidados Primários de Saúde, em 1978, quando se propôs a atenção primária à saúde como uma estratégia para ampliar o acesso de forma igualitária a população até o ano 2000, sendo que tais concepções enfocam: "[...] um médico ou profissional de saúde com formação e desempenho não somente clínico (curativo) mas também, e sobretudo, com a concepção epidemiológica e social, para um modelo de atenção em que haja a predominância e prioridade para a Promoção e Prevenção, com uma relação profissional de saúde - indivíduo - família - comunidade".

Assim, a "saúde da família"é vista hoje como uma estratégia de reorganização sanitária e como uma das alternativas para a reconfiguração da Atenção Primária à Saúde.

A proposta do Programa de Saúde da Família (PSF), do Ministério da Saúde, faz parte de uma estratégia desenvolvida para promover mudanças no atual modelo de assistência à saúde do pais que tem prioritariamente se voltado para atenção à cura e em menor proporção à prevenção das doenças. A compreensão do PSF, no modelo atual, só é possivel através da mudança do objeto de atenção, da forma de atuação e da organização geral dos serviços, reorientando a prática assistencial em novas bases e critérios.

De acordo com BRASIL (1998) "Essa perspectiva faz com que a familia passe a ser o objeto precipuo de atenção, entendida a partir do ambiente onde vive. Mais que uma delimitação geográfica, é nesse espaço que se constróem relaçōes intra e extra-familiares e onde se desenvolve a luta pela melhoria das condiçōes de vida - permitindo, ainda, uma compreensão ampliada do processo saúde-doença e portanto, da necessidade de intervenções de maior impacto e significação social".

A estratégia de saúde da familia tem essa proposta e "elege como ponto central o estabelecimento de vinculos e a criação de laços de compromisso e de co-responsabilidade entre os profissionais de saúde e a população" (BRASIL, 1998). Propõe trabalhar na perspectiva da vigilância à saúde, com responsabilidade integral sobre a população que reside na área de abrangência de suas unidades de saúde.

\section{OBJETIVOS}

Considerando este quadro traçado, esta investigação tem por objetivo estudar a percepção dos trabalhadores de enfermagem quanto à configuração de sua prática assistencial na atenção à Saúde da Familia, tomando por foco os trabalhadores que atuam no Programa de Saúde da Familia no municipio de Batatais. Os objetivos específicos são:

- Caracterizar e analisar a percepção dos trabalhadores de enfermagem quanto ao desenvolvimento das ações de enfermagem em atenção primária;

- analisar a percepção dos trabalhadores de enfermagem quanto aos instrumentos e saberes utilizados em sua prática cotidiana, de atenção à saúde da familia.

\section{PERCURSO METODOLÓGICO}

O estudo realizado é de natureza exploratória e descritiva e está sendo apresentado em forma de estudo de caso, onde o cenário de estudo do PSF é o município de Batatais. Segundo Lüdke e André (1986), o estudo de caso, seja ele simples e específico ou complexo e abstrato, deve ser delimitado, deve ter seus contornos claramente definidos no desenrolar do estudo, "quando queremos estudar algo singular, que tenha um valor em si mesmo, devemos escolher o estudo de caso".

\section{PROCEDIMENTOS METODOLÓGICOS}

Dentro da Divisão Regional da Saúde XVIII - DIR XVIII do estado de São Paulo, tinha-se 
até Dezembro de 1998, dos 25 municipios que a compunham, 3 que vinham desenvolvendo o Programa de Saúde da Familia: Batatais, Barrinha e Cajuru.

Realizamos uma caracterização geral destes municípios através de dados secundários obtidos junto à DIR XVIII, e encaminhamos aos Secretários Municipais de Saúde de cada municipio o resumo do projeto solicitando a autorização para o desenvolvimento da pesquisa. Como o município de Batatais foi o que apresentou-se mais prontamente disponivel para a realização da pesquisa, selecionamos o mesmo para o presente estudo.

Num primeiro momento foram obtidas informações acerca da caracterização geral do municipio através de dados fornecidos pelo Departamento de Saúde do município de Batatais.

Num segundo momento, buscou-se obter a caracterização geral dos trabalhadores do PSF e sua percepção quanto ao programa, sendo que o instrumento selecionado para esta fase foi a entrevista semi-estruturada. A coleta de dados foi realizada de fevereiro a abril de 1999. É importante salientarmos que o projeto foi encaminhado ao Comitê de Ética em Pesquisa da EERP - USP, que após análise autorizou a sua realização.

Os entrevistados foram os trabalhadores de enfermagem e agentes comunitários de saúde que atuam no Programa de Saúde da Familia no municipio de Batatais.

Para a etapa de análise dos dados, utilizamos "Análise Temática", que segundo Minayo (1998),"[...] consiste em descobrir os núcleos de sentido que compõem uma comunicação cuja presença ou freqüência signifiquem alguma coisa para o objetivo analítico visado". As unidades temáticas identificadas no processo e analisadas foram: integralidade, cuidar da saúde, ir em busca do usuário e vínculo.

\section{O TRABALHO DE ENFERMAGEM NO PSF EM BATATAIS}

\section{CARACTERIZAÇÃO GERAL DO MUNICÍPIO EM ESTUDO}

O municipio de Batatais está localizado na região Nordeste do Estado de São Paulo, distando $315 \mathrm{Km}$ em linha reta da capital. Ocupa uma área total de $838 \mathrm{Km}^{2}$ sendo $18 \mathrm{Km}^{2}$ Zona Urbana e $820 \mathrm{Km}^{2}$ Zona Rural. Situa-se na Área de Saúde da Micro Região IV, coordenada pela Direção Regional de Saúde de Ribeirão Preto - S.P. (DIR XVIII), estando em Gestão Plena do sistema municipal de saúde.

A população de Batatais segundo dados do plano Diretor de Saúde para o município (1998) a projeção é de $\mathbf{4 8 . 9 3 4}$ habitantes com estimativa de 44.530 residirem na Zona Urbana e 4.404 na Zona Rural, para o ano de 1998 . Sendo que $56,1 \%$ săo jovens com até 29 anos e que $9,60 \%$ enquadram-se na faixa etária de individuos com mais de 60 anos.

Existe disponivel na rede municipal 6 unidades de saúde pública, o Asilo dos Pobre de Batatais, Serviço Auxiliar Diagnóstico de Terapia, APAE e o Hospital Santa Casa de Misericórdia que atende através de convênio particular e o SUS, o hospital possui 104 leitos, com 90 para o atendimento do SUS e 14 para o particular.

\section{CARACTERIZAÇÃO DA EQUIPE DO PROGRAMA DE SAÚDE DA FAMILIAA DE BATATAIS}

OPSF em Batatais começou a funcionar em junho de 1998, estando instalado em parte de uma unidade do núcleo CAIC (Centro de Atenção Integral à Criança), localizado na área industrial da cidade, próximo à periferia e a microárea onde presta assistência.

Segundo preconiza o Ministério da Saúde "É recomendavel que a equipe de uma unidade de Saúde Familia seja composta, no minimo por um médico de familia ou generalista, enfermeiro, auxiliar de enfermagem e agentes comunitários de saúde (ACS). Outros profissionais poderão ser incorporados a estas unidades, $d$ acordo com as demandas e características de organização 
dos serviços locais de saúde" (BRASIL, 1998).

A equipe de Batatais é formada por 1 enfermeira, 2 auxiliares de enfermagem, 4 agentes comunitários de saúde, 1 dentista contratado no mês de fevereiro de 1998, 1 médico generalista.

Algumas características desta equipe que nos chama atenção: a alta escolaridade dos ACS, que possuem nível universitário em outras áreas que não na da saúde, o que parece facilitar o entendimento das suas ações no programa, no entanto pode significar uma dificuldade de obter empregos na cidade. Os auxiliares de enfermagem possuem experiência prévia na saúde, um na área hospitalar e outro na área de atenção básica de saúde. A enfermeira possui experiências anteriores tanto na área pública (unidade básica), quanto na área hospitalar. Todos da equipe realizaram capacitação especifica promovida pela Escola de Enfermagem de Ribeirão Preto-USP.

\section{A PERCEPÇÃO DOS TRABALHADORES}

Aqui serão apresentados os temas identificados na fala dos trabalhadores em relação às suas atividades no PSF.

\section{INTEGRALIDADE}

Tomando como marco referencial a Constituição Brasileira (BRASIL, 1989), a integralidade da assistência é colocada como um princípio orientador do Sistema Único de Saúde - SUS. Entendemos a integralidade referindo-se "tanto ao homem quanto ao sistema de saúde, reconhecendo-se que cada qual se constitui numa totalidade. Assim, cada pessoa constitui um todo indivisivel e membro de uma comunidade; ações de promoção, proteção e recuperação da saúde da mesma forma se constituem em um todo, não podendo ser compartimentalizadas; as unidades constitutivas do sistema configuram também um todo indivisivel, capaz de prestar assistência integral" (IBAN/UNICEF, 1991).

No discurso dos trabalhadores é possivel identificar 3 dimensões da integralidade: integralidade numa perspectiva holística de atenção ao homem; integralidade do sistema de saúde, levando-se em conta os diferentes níveis de atendimento e integralidade num sentido mais amplo, entendendo-o a efetivação da ação intersetorial. É importante salientarmos que tais aspectos embora separados para efeito de análise apresentam-se de forma complementar.

O programa se constitui em uma estratégia para reversão do modelo que atualmente temos como predominante, onde de verifica preferência pelas ações individuais e curativas, com atendimento de alta complexidade / especialização e desumanização nas relações profissional - usuário. Há, portanto, a proposta de que se institua outra lógica para o desenvolvimento das ações de saúde, e que os trabalhadores possam tomar o indivíduo como um ser de necessidades que precisam ser satisfeitas no seu todo e não enquanto partes sem articulação.

Verifica-se no discurso dos trabalhadores uma relevância a esta questão quando falam: Diferente o enfoque do doente, diferente, de tratar uma pessoa inteirinha, sabe năo é aquela história de médico ... Acho que a medicina se dividiu tanto, tanto, tanto, ficou tão especializada, que hoje volta o antigo médico de família que é uma coisa antiga. Sabe, que faz você enxergar a familia como um todo, a pessoa no seu lar né, que é diferente, entăo eu acho que está voltando, sempre depois de uma revoluçăo vem a volta e o resgate dos antigos principios e isso é muito importante. (ENTREVISTA1)

Uma compreensão ampliada do processo saúde-doença e de suas determinações permitindo ver o individuo como um todo, inserido e produzindo-se no seu meio biopsicossocial, 
onde o profissional de saúde tenha a possibilidade de atuar holisticamente, não se restringindo apenas a procedimentos específicos da saúde parecem ser questões presentes nesta nova lógica presente no PSF. A fala a seguir representa bem o que tentamos explicar: Além de material curativo, termómetro, aparelho de pressão, se fosse mesmo produzir, funcionar, a gente precisaria trabalhar com agulhas, linhas para ensinar este povo a fazer croche para se distrair que acabaria com a maior parte das depressões que nós temos, tá assim conseguir alguma coisa para elas fazerem, sabe assim sabão em casa, tapete, bordado, para as crianças eu já pensei muito e já até falei com a enfermeira, porque nós temos a faculdade de educação física aqui, teria que entrar em contato, montar escolinha para as crianças sabe, de esportes, sabe, precisaria de bola, várias outras coisas. (ENTREVISTA2).

Mesmo os Agentes Comunitários de Saúde que não possuiam experiência prévia na área da saúde, possuem uma compreensão de totalidade do individuo, relacionando-o com a família e o meio em que vive, pois tem a seguinte fala: Saúde da família eu acho que é o que a gente esta tentando fazer al, é por exemplo ver a pessoa num todo, não como se vê na maioria das vezes dentro do hospital o paciente, porque lá o paciente tem um número, e uma ficha, aqui para a gente não, é um todo, a gente vê a familia toda, a gente consegue encaixar a pessoa dentro da família. (ENTREVISTA5)

Para se chegar nesta assistência integral ao indivíduo, uma questão importante a ser observada é o desenvolvimento do trabalho realizado em equipe, pois muitas vezes o indivíduo é cuidado por todos na equipe. O "problema" é identificado pelo agente comunitário de saúde, o auxiliar faz curativos e orientações, a enfermeira vai na visita em algumas situações específicas e o médico a consulta, cada profissional complementando a assistência prestada pelo outro, não se somando apenas as atividades. E estas informações ficam registradas no prontuário familiar de modo que possa haver continuidade na assistência como podemos verificar neste fragmento de entrevista: ... porque a gente vai, dá uma assistência na casa, a gente vai para ver como está o estado geral de saúde da família, tem os auxiliares que trabalham, que vão fazer curativo, vão fazer uma orientação um pouco mais complexa, tem a enfermeira, o próprio médico né, que na sexta-feira passada mesmo ele foi, então ele vai na visita ... (ENTREVISTA6)

No discurso dos trabalhadores é evidenciado que ao se cuidar da família como um todo, tem-se a possibilidade de envolve-la na resolução do seu problema, de forma que todos os membros possam estar contribuido para a sua solução. Há portanto, nos discursos um novo ponto de partida para a atuação dos trabalhadores, sem perder de vista a singularidade de cada um, entra em cena um novo sujeito: a familia.

Estudos de Dominguez (1998) indicam que do ponto de vista de atenção da saúde devese levar em conta que a família é a "causa de muitos problemas", no entanto se mostra como "recurso para prevenir e resolver muitos outros".

Desta forma, o profissional tem a possibilidade de incentivar a família no desenvolvimento de sua autonomia, estimulando o exercício da cidadania.

Quando nos referimos a integralidade do sistema, esta se torna necessária e fundamental, pois mesmo atuando na Atenção Primária com atividades centradas na prevenção, na profilaxia e tratamento de agravos especificos, é necessário a referência para unidades de maior complexidade assistencial, sendo que esta retaguarda de outros niveis traz maior segurança na atuação dos trabalhadores, como nos mostra a fala: ... porque trabalhar com o PSF vinculado com um hospital de retaguarda isso é legal e vi algumas unidades que trabalham com postos, mas sempre vinculados a um atendimento que eles fazem e eu acho que a idéia de saúde é essa, tá. É você tentar resolver os problemas que a gente consegue na população mesmo e encaminhar para atendimento terciário ou qualquer assim quando é extremamente necessánio para tentar segurar o máximo que a gente tem. Entăo eu acho importante ter um hospital de retaguarda, dá muita segurança saber que deixou a sua população, mas que qualquer coisa, você tem um hospital, vocé tem os exames, para a gente estar agilizando essas coisas. 


\section{(ENTREVISTA1)}

Além disso, é importante a busca de uma ação mais integrada com outros setores que não somente os da saúde, pois segundo estudos de Minayo (1998), "Não existe nenhuma altemativa de solução dos problemas de saúde da população brasileira que possa ser buscada apenas no interior do próprio setor saúde."

Por isso apontamos a necessidade de uma efetiva integração não só do PSF, mas dos serviços denominados de Atenção Primária à Saúde, ou mesmo aqueles da saúde de forma geral com os equipamentos sociais disponiveis na comunidade. A partir do momento em que olhamos para esta população compreendendo a determinação do processo saúde-doença, diversas outras necessidades são identificadas como influenciadoras no estado de saúde como citado nesta fala: A gente está tendo muita coisa, então por exemplo a gente precisa de uma coisa mais urgente, uma pessoa até mesmo em outras áreas, a gente vê que a pessoa está passando dificuldade financeira a gente tenta encaminhar, a enfermeira conversa com as assistentes sociais né, tenta conseguir alguma coisa para essa pessoa e a resposta deles é muito boa. "(ENTREVISTA4)

Minayo (1998), coloca que "A epidemiologia social encontra seu limite no paradigma que institui apenas o corpo como seu espaço de saúde-doença. Seu desafio é encontrar na teoria e na prática a totalidade fundamental do ser humano".

Acrescentar "as agulhas e linhas" ao arsenal já conhecido como "termômetros e aparelhos de pressão" e, considerar a forma como o PSF em espaços especificos está construindo este novo individuo (integralmente), pode ser um caminho para pensarmos na conquista deste desafio colocado por Minayo (1998).

\section{CUIDARDA SAÚDE}

Quando os trabalhadores de enfermagem falam do seu trabalho no PSF é marcante este termo cuidar da saúde, aparecendo em vários sentidos: prevenção; orientação; planejamento das ações; melhora das condições da família.

A prevenção é apontada como uma das principais caracteristicas definidoras do trabalho no PSF, como podemos verificar nesta fala:... Programa de Saúde da Familia ele trabalha com a prevenção, então é muito importante... (ENTREVISTA1)

Porém, em alguns momentos esta fala se torna perigosa quando se exclui do programa as atividades curativas que podem restaurar o estado de saúde, reduzindo o PSF apenas à prevenção como esta:... então nós vamos trabalhar é em cima da saúde, a gente vai estar buscando mais do que nunca a saúde, então tira o lixo da sua casa porque o lixo lá tem rato, rato transmite doença, então a gente vai trabalhar tudo em cima da saúde, não é curar, enfim é da saúde... (ENTREVISTA1)

Parece-nos uma perspectiva limitada do trabalho, e em certa medida contraditória com as questões colocadas em relação à integralidade, uma vez que ações voltadas ao tratamento, e à reabilitação de agravos casos acontecem neste nivel de atendimento e são tão importantes quanto as de prevenção em determinadas situaçōes.

Os auxiliares de enfermagem, por outro lado, talvez por sua formação ou atividade específica que desenvolvem no programa, ou seja muitas atividades assistenciais curativas, apresentam outra concepção em relação as atividades de prevenção.

Quando trazem esta fala: Não, a parte curativa vocé sabe que eu acho assim que é até digamos assim, necessária, mas eu acho que tem que ir além da parte curativa, porque a parte curativa, a pessoa machucou ela vai no Pronto Socorro ela tem o curativo, entendeu, então eu acho que não é só a parte curativa é a parte moral da pessoa, tentar restabelecer ela. (ENTREVISTA2). Há uma preocupação que o conjunto das atividades assistenciais a serem desenvolvidas, tenham maior abrangência, ou seja, não descartam a necessidade e a efetiva 
realização de atividades curativas, no entanto vêem necessidade de associá-la à ações preventivas.

Os agentes comunitários de saúde complementam esta idéia quando falam que a população entende a saúde voltada para a ótica curativa, referindo à saúde como sendo a ausência de doença. Desta forma, os agentes identificam a necessidade de conscientizar essa população quanto ao conceito mais amplo de saúde, assim como a importância de se trabalhar a mudança de hábitos para alcançarem uma melhor qualidade de vida. Entendem que o cuidar da saúde é antes de tudo ensinar as pessoas a ter saúde e a cuidar da sua saúde, possibilitando desta forma maior poder de decisão e autonomia por parte da população. Ensinar as pessoas a se cuidar para ela nåo ficar doente. É um ponto chave do programa né ... porque é o objetivo dele mesmo né, cuidar da saúde para não ter que cuidar da doença. (ENTREVISTA6)

Outra questão presente no discurso dos trabalhadores é o planejamento das ações a serem realizadas, que implica em conhecer bem a população a quem se prestará o cuidado, identificando suas caracteristicas e necessidades: ... a gente não vai muito cedo, a gente vai oito, oito e meia, porque os dias que a gente vai muito cedo a gente năo acha ninguém acordado ... (ENTREVISTA1)

Ao planejar as ações algumas expectativas devem ser atentadas pelos trabalhadores, principalmente os agentes comunitários de saúde que possuem uma maior proximidade com a comunidade e algumas vezes tem que lidar com situações em que alguém da familia não está disposto a atendê-lo. Entender essas situaçōes e replanejar as atividades pode ser necessário se levarmos em conta o contexto da vida da família, o tempo necessário para o estabelecimento das relaçōes entre clientela e trabalhadores e a subjetividade presente nestas relaçōes humanas. Como podemos verificar neste fragmento de entrevista: Agora depende também da colaboração das pessoas né, quando a gente chega numa casa e a pessoa não está muito afim, porque às vezes está com dor tudo né, mas às vezes você chega num dia que ela a pessoa não está muito bem, a mulher está com uma cara, então tem que ter paciência, hoje ela não está muito bem, depois eu volto outro dia. Entăo săo problemas que a gente enfrenta e que são naturais dos seres humanos, eu mesmo quando levanto de manhă, tem dia que dá vontade de descarregar no primeiro que passa né, o primeiro que bate na porta leva né. Como a gente até acorda algumas, as vezes a gente leva né. (ENTREVISTA6)

Cuidar da saúde também é entendido como melhorar as condições da familia, de modo a se buscar uma solução para os problemas de forma mais humana, sendo comum falas expressando sentimentos como: solidariedade, ajuda ao próximo e gratificação do trabalho realizado: ... eu tô cuidando eu vou lá, eu atendo um velhinho, talvez uma criança, então é uma forma parece que de solidariedade assim direta, você ir, você cuidar. (ENTREVISTA6)

Boff (1999) discutindo o cuidado como o valor mais fundamental constitutivo do ser humano afirma que: "O que se opõe ao descuido e ao descaso é o cuidado. Cuidar mais que um ato, é uma atitude. Portanto abrange mais que um momento de atenção, de velo e de desvelo. Representa uma atitude de ocupação, preocupação, de responsabilização e de envolvimento afetivo com o outro".

Entendemos que, ainda que timidamente, a fala dos trabalhadores, em especial estas duas últimas, reiteram a afirmação de Boff (1999), uma vez que o cuidar da saúde evidenciado, mesmo levando em conta seus diferentes sentidos, apontem para a conformação / construção de uma atitude mais humana na atenção à clientela, de se criar uma rede de solidariedade assim direta, você ir, vocé cuidar.

\section{IREM BUSCA DO USUÁRIO}

PSF parece trazer aos trabalhadores a preocupação em cuidar da saúde, e este cuidar traz também o ir em busca do usuário, esta é mais uma das idéias que perpassa a fala 
dos entrevistados, mas o que queremos dizer com esta expressão? O PSF possui uma diferente lógica na organização da assistência à clientela. É um modelo de assistência à saúde do individuo, da familia e da comunidade, sua equipe faz atendimento na unidade local de saúde e na comunidade, trabalhando não apenas com a demanda espontânea de uma determinada área e sim indo até a população, estabelecendo vínculos e criando laços de compromisso e coresponsabilidade, resgatando a perspectiva de uma atenção humanizada, pois o mesmo apresenta como objetivo:"[...] contribuir para a reorientação do Modelo Assistencial a partir da Atenção Básica, em conformidade com os princípios do SUS, imprimindo uma nova dinâmica de atenção nas Unidades Básicas de Saúde, com definição de responsabilidades entre os serviços de saúde e a população." (BRASIL, 1998).

O início deste contato com a comunidade se estabeleceu com o cadastramento das famílias de uma área geográfica, onde são identificados os integrantes familiares e as condições gerais do meio onde esta familia está inserida.

Desta forma, o serviço vai até o usuário, identificando possíveis problemas e necessidades para o desencadeamento de ações que visem uma melhor qualidade de vida desta população. Assim, a família e o seu espaço social passam a ser eleitos como "núcleo básico de abordagem no atendimento a saúde" (BRASIL, 1998).

Segundo a percepção dos auxiliares de enfermagem, em sua maioria, trabalhadores que já tem uma experiência prévia em serviços de saúde anteriores definem esta atividade como ir na casa e descobrir o problema, como pode ser verificado nas falas a seguir: Diferente porque no hospital eu estou na minha casa e o paciente me procura, agora não, eu vou, os agentes... identifica o problema ... (ENTREVISTA3)

Com esta mudança no fluxo dos usuários ao serviço, as relações entre pacientes e trabalhadores de enfermagem fatalmente são alteradas, a instituição de saúde não é mais o palco principal de atuação dos trabalhadores em sua relação com os usuários, sendo este agora a casa deste usuário, como podemos verificar nesta fala: Tem algumas pessoas que sentem mais necessidade do poder de domínio, se você chega e me pede uma consulta eu vou responder para você tenho ou não tenho, você está me procurando. Agora eu vou chegar na tua casa, perguntar para você qual o teu problema, o que você tem ... não é diferente? É uma forma diferente de você ver, porque você sempre é a dona da casa entendeu? Você muda de lado e é muito interessante. (ENTREVISTA1)

Fora das paredes institucionais, agora não mais o trabalhador possui todo o poder de decisão e a responsabilidade em definir ações que julga necessárias, o usuário passa exercer ou não sua autonomia, liberdade e "cidadania", como discutiremos a seguir.

Outra questão importante a ser abordada é a de que com o atual Modelo Assistencial, o paciente é tratado apenas por partes com base na queixa-conduta (pronto atendimento). Segundo estudo de Minayo (1998) “O Modelo Biomédico pode propor a cura de uma enfermidade localizada, mas não possui um quadro de referência para lidar com as sensações experimentadas no corpo marcado pela exclusão dos bens necessários à manutenção da vida individual e social".

Tomando-se o PSF enquanto estratégia de mudança de modelo, tem-se a possibilidade de enxergar para além das partes, ou seja, o indivíduo e não só este como um todo, mas inserido em seu contexto biopsicossocial, no meio em que vive e nas suas relações com os demais familiares influenciando no processo de saúde-doença. Por exemplo: Você fica caçando problema da pessoa, enquanto que lá não, eles iam e só contavam aquilo que estava ali, e a gente na casa da pessoa a gente vai mais além, então às vezes uma coisa você acha que não tem nada à ver, você vai mais um pouquinho a fundo e a razão do problema da pessoa está ali (ENTREVISTA2)

Com esta nova ótica de organização da assistência, os trabalhadores tem a possibilidade concreta de conhecer realmente os usuários e o meio no qual estes vivem. Este aspecto é de suma importância, pois o conhecimento do contexto social destes indivíduos possibilita a 
identificação de suas reais necessidades e a adequação das orientações / intervenções a esta realidade. Por exemplo: Entăo é muito importante a gente enxergar a pessoa dentro da casa dela com as dificuldades, as carências alimentares, as carências financeiras, com todas as dificuldades que ele tem, tem muitas familias que não tem condição, a gente orienta sobre o lixo, elas năo tem condiçăo de comprar o saco de lixo tá, então você trabalha dentro da vida deles e a gente tá indo assim. (ENTREVISTA1)

Se por um lado há uma maior proximidade com a realidade e as necessidades dos usuários / famílias / comunidade, por outro há uma "exposição" do trabalhador a um universo de questöes antes distantes. Os trabalhadores, dentro da instituiçăo, estavam protegidos desta realidade de vida do usuário, não precisando enfrentar e se envolver em muitas situaçōes dificeis como: a ausência de trabalho, o desemprego crescente, a falta de condições adequadas de vida, a pobreza e as carências de várias ordens. Devemos salientar que estas características aqui colocadas não são exclusivas desta área a qual se destina o PSF, pois grande parte da sociedade brasileira passa por este tipo de dificuldades devido ao contexto sócio-econômico no qual estamos inseridos.

O que a gente vê é muita pobreza, muita fome, tá, muita necessidade, então a gente teria que ter uma assistente social com a gente para agilizar o serviço, para estar conseguindo cesta básica para o pessoal porque a maioria está desempregado, tem uma outra coisa, uma frente de emprego para essas pessoas, que está difícil e vocé vé este pessoal todo na rua e não tem o que fazer, não adianta você falar não você tem que trabalhar porque ele não arruma emprego, a crise está aí, está feia, então muitas das vezes ele não tem o que comer porque não tem emprego, e aí o que acontece, eles caem no alcoolismo e aí o que fazer... (ENTREVISTA2). Na fala desta auxiliar é evidente que outros aspectos ligados ao modo e às oportunidades de vida do usuário, determinam seu estado de saúde e atesta a necessidade de uma articulação com outros trabalhadores / setores para além da saúde, a fim de buscar alternativas de intervenção sobre as situações identificadas e que mereçam uma ação mais efetiva dos trabalhadores de saúde.

Lidar com tais questões, que acabem por expor a limitação da ação do setor saúde nas situações cotidianas de vida é sempre dificil e sofrido, muitos dos trabalhadores entrevistados referem que o sofrimento está sempre presente, como nesta fala: Então, é um pouco desgastante, você vê muito sofrimento e não pode fazer nada, o que a gente faz é mínimo. (ENTREVISTA2)

Tais falas encaminham para um aspecto bastante importante na ação em saúde que diz respeito à humanização do atendimento. Ou seja, como lidar com a "dureza da vida" sem permitir que esta exposição diária nos deixe (trabalhadores da área da saúde) ou "insensiveis e duros" a esta realidade ou tomados apenas por sentimentos altruistas e assistencialistas.

Segundo estudos de Schraiber e Mendes-Gonçalves (1996) durante muito tempo se teve uma "intervenção humanizada" na assistência à saúde, realizado principalmente pelos médicos de familia, época esta em que não se tinha tanta competição no mercado de trabalho. "Contudo, com a produção de serviços em larga escala e passando os trabalhos a serem organizados segundo as complexas estruturas das instituiçōes, este fato tornou-se inevitável uma certa despersonalização nos cuidados prestados. Devemos notar que algum distanciamento será sempre desejável, por sermos profissionais que, ao menos por um dos ângulos de nossa prática, tomamos o sofrimento por ofício. Neste sentido, nossas técnicas e seu aprendizado devem situar-se de modo a evitar o imobilismo ou o pânico diante da dor. Mas entre este bem adequado distanciamento e uma total desumanização, há um espaço no qual devemos atuar" (grifo nosso).

Tendo em vista que um dos objetivos específicos para o desenvolvimento do PSF é a humanização das práticas da saúde através do vinculo entre profissionais e população, ainda há um caminho a percorrer na busca deste espaço ideal para se trabalhar colocado por estes autores. 


\section{VÍNCULO}

Nos depoimentos dos trabalhadores, é apresentado uma característica marcante do Programa de Saúde da Familia: o vínculo criado nas relações entre a equipe e a população usuária. Importante lembrarmos que mesmo enquanto proposta o estabelecimento de vínculo era colocado em destaque. "assim, o PSF elege como ponto central o estabelecimento de vinculos e a criação de laços de compromisso e co-responsabilidade entre os profissionais de saúde e a população" (BRASIL, 1999).

Campos (1997) traz em sua discussão sobre modelos assistenciais a "noção de vínculo", afirmando ser este "a pedra de toque de qualquer projeto que pretendesse mudar os modos de atenção".

A temática vínculo é evidenciada nas falas nas dimensões: necessidade de atenção; confiança necessária; autonomia ou dependência?

Os agentes comunitários de saúde e os auxiliares de enfermagem principalmente entendem que a "carência"é um fator facilitador do estabelecimento de vínculo, pois a população tem uma grande necessidade de atenção.

Estudos de Schraiber e Mendes-Gonçalves (1996) demonstram que a demanda aos serviços de saúde geralmente se dá devido a carecimento: "[..] algo que o individuo entende que deve ser corrigido em seu estado sócio vital. Pode ser uma alteração física, orgânica, que o impede de seguir vivendo em sua própria rotina de vida, ou um sofrimento ainda não identificado fisicamente; ou até uma situação que reconhece como "uma falta" algo que carece, como por exemplo uma informação".

A partir da sensibilidade e do entendimento que a equipe tem de que estas necessidades de atenção podem ser importantes para a saúde do indivíduo e da família, os trabalhadores evidenciam sua preocupação, na medida do possivel em tentar sanar esta necessidade, ouvindo e demonstrando interesse pelo problema do usuário mesmo que a solução esteja longe de seu alcance.

É muito marcante e significativa a fala dos profissionais quando referem que a população tem a necessidade de ser ouvida e ter com quem conversar. Será que todos os profissionais estão dispostos a ouvir? Isso é importante para o usuário? Estabelecer um espaço para a "escuta" se viabilizar não é importante? Este exemplo complementa a nossa discussão: Eu acho que o Programa de Saúde da Familia é isso daí e a gente vê a pessoa num todo, de um problema da pessoa, năo tratar a pessoa como um número, uma fichinha que aparece lá de vez em quando, que aparece mais lá, que todo fim de semana está no hospital, entendeu, que na maioria das vezes, a pessoa fala ah, você gosta de vir para o hospital, năo sei o que lá, e às vezes é pura carência, porque lá tem enfermeira que vai ficar lá, e vai chegar e falar ah bem, o que vocé tem? Às vezes é pura carência aquilo ali, precisa um pouco de atençăo. (ENTREVISTA5)

Com a organização da assistência centrada no modelo biomédico, onde só as partes são tratadas e só a queixa centrada numa doença traz a possibilidade da pessoa ser atendida pelo serviço, não existe o espaço para se entender estas "necessidades de atençăo" da população, o que pode ser uma das razōes para a demanda excessiva e sem resolutividade de alguns serviços, pois muitas vezes não se busca um tratamento específico (este é só um pretexto para ter acesso ao serviço), pois o que realmente se busca é "ATENÇÃO" (Campos, 1997).

Para o estabelecimento de relações de vínculo uma questăo importante colocada nas entrevistas é a confiança necessária. Esta confiança muitas vezes se dá após o reconhecimento do profissional como sendo aquele individuo responsável pelo seu tratamento, passando a tê-lo como uma referência. É aquele que vai cuidar da saúde, que se preocupa e se responsabiliza pela atenção do outro, por exemplo: ... é completamente diferente, porque eu que vou na casa do paciente sendo que antes eles que vinham procurar, antes eles chegavam numa unidade, num hospital e cada vez era um que atendia, tá, nem sempre era o mesmo e hoje não sou eu 
que vou, só eu... (ENTREVISTA3)

Esta relação pode ser entendida como benéfica para ambos os lados (trabalhador / população). Os trabalhadores podem ver a evolução do seu trabalho, assim como o resultado do mesmo, constituindo-se como a sua "OBRA". Segundo Campos (1997) a divisão do trabalho e as especializações levam a uma separação entre o trabalhador e a "OBRA", eles fazem parcelas do trabalho (intervenções) e não se responsabilizam pelo objetivo final da própria intervenção, tornando-se atos esvaziados de sentido. O reconhecimento de um trabalho bem feito, realizado com compromisso e vontade, evidenciado uma "atitude" voltada para o cuidado e não para o ato, entusiasma e faz com que o profissional se sinta valorizado e estimulado para continuação do mesmo.

Por sua vez a população sente-se mais segura ao saber que tem um trabalhador de saúde de referência, responsável por sua saúde, compromissado em tentar resolver ou encaminhar alternativas de solução de seus possiveis problemas, quando falam que: ... na maioria das vezes você passa a ser confidencial tudo ali, até relação sexual, briga de marido eles te contam, e a vida da pessoa, então tudo os problemas eles te contam, porque você está no dia a dia ... (ENTREVISTA2).

Campos (1997) afirma: "a ligação um pouco mais estável e duradoura entre profissional e paciente permitiria que o último exercesse melhor seus direitos de cidadania. Afinal ele reconheceria o nome, o posto e as atribuições dos responsáveis pelo seu cuidado."

Neste sentido, podemos perceber como no exemplo citado que o usuário se sente com maior liberdade em revelar problemas até mais intimos que provavelmente não abordaria se tivesse na unidade de saúde, onde o distanciamento entre a equipe e a clientela esta presente em diferentes situações: o vidro no balcão, a pressa no atendimento, as proibições expressas em cartazes (Matumoto, 1998).

A partir dessa relação de confiança estabelecida com os usuários os profissionais perceberam que houve uma maior adesão ao programa, pois provavelmente a população se sentiu cuidada.

E desta forma a confiança na equipe se faz importante e necessária no sentido em que se pode estimular a autonomia da população, como podemos perceber nesta fala: A gente não tem, vai atrás, e eles também a gente põe na cabeça deles que eles tem que ir atras e é o que está acontecendo a gente tem resposta eles vão atrás mesmo. (ENTREVISTA4)

Finalmente, um último aspecto de análise diz respeito a autonomia esperada em contraposição a dependência algumas vezes criada. Como estas opostas relações se dão ou talvez até se complementem?

Ao abordarmos sobre a diferença que existe quando o paciente vai em busca do serviço e quando este vai até a sua casa, colocamos a possibilidade do usuário possuir maior autonomia para decidir sobre a sua vida. Com esta mudança na relação trabalhador / usuário existe uma necessidade de recompor-se a relação: quem manda em quem? será que alguém tem que mandar? de quem é o poder de decisão agora?

Em alguns momentos a população se mostra autônoma, enquanto que em outros é extremamente dependente e submissa como veremos nos exemplos a seguir. .. entăo a gente tem que envolver a familia para todo mundo tentar resolver o problema, porque sem a colaboração da família a gente não consegue muita coisa năo. (ENTREVISTA4)

Alguns profissionais demonstram ter consciência da importância da conquista da autonomia pela população, estimulando a participação, o envolvimento e a co-responsabilidade desta nas ações propostas e no cuidado à saúde. E alguns tem até a compreensão de que não tem poderes sobre decisões da população. ... com certos casos que vocế vê, sabe então você tem que ter muita boa vontade, paciência porque tem muita gente que não te escuta, que não adianta, e vocé tem que saber que năo é o todo poderoso, que vocé tem que ter calma, perseverança, tem muita gente que dá trabalho ... (ENTREVISTA7) 
Quando a população procura o serviço de saúde o trabalhador tem a possibilidade de mostrar-se "poderoso", permitindo o acesso da população, isto nem sempre ocorre quando se vai em busca da população, ultrapassando os muros das unidades de saúde. Ainda algumas vezes a população fala o que o profissional quer ouvir para não perder a possibilidade de acesso ao serviço de saúde. O que eu acho mais difícilé quando você vê que a pessoa está necessitada de um atendimento, você vai, marca, você decide faz tudo o que tem que fazer e a pessoa não dá a resposta que você quer, não vai à consulta ... (ENTREVISTA4)

Nestas falas há um certo pesar dos trabalhadores, pois a população nem sempre se mostra susceptível ao que é colocado / decidido pelos trabalhadores.

É de certa forma a maneira que os usuários encontraram para exprimir sua possibilidade de decidir contrariamente ao que lhe foi colocado.

Um sentimento que pode aflorar em alguns profissionais é o da frustração quando percebem que agora não mais são os únicos detentores do poder de decisão apenas por serem os detentores do conhecimento e da verdade, nem sempre o que ele pensa ser melhor para o paciente é realmente o que ele necessita para sobreviver e ser feliz.

Talvez até por esta razão em algumas situações podemos verificar momentos de autoritarismo, onde a população pode se sentir coagida e dominada como podemos verificar nesta fala: ... eles respondem muito bem a gente, tudo, tudo, a não ser alguns que a gente marca consulta e não vem, né, mas aí você vai lá, dá um puxão de orelha, tá. (ENTREVISTA4)

Alguns exemplos também nos mostram situações de extrema dependência à equipe como esta, aparecendo a questão do paternalismo e da acomodação da clientela como uma relação negativa: ... não sei se de repente a gente se torna um paternalista para eles, você vê eles não fazem nada sem a gente aqui agora, para marcar uma consulta eles correm atras da gente na rua e eu acho que não é por al, você tem que ensinar... (ENTREVISTA7)

Certamente autonomia e dependência são pares contraditórios que se constróem em sua oposição, mas é fundamental se ter a frente que a conquista da autonomia e da liberdade é um processo a ser construído, tanto os trabalhadores quanto os usuários estão aprendendo a conviver com esta nova dinâmica de relações e divisão de poderes que se faz presente no PSF.

\section{CONSIDERAÇÕES FINAIS}

Apresentaremos algumas considerações, sintetizando e discutindo os dados empíricos, relacionando-os com os objetivos propostos.

Os trabalhadores de enfermagem tem a percepção de que a prática assistencial na atenção à saúde da família é voltada a integralidade da assistência, seja ela nos diversos níveis: de ver o indivíduo como um todo à integralidade do sistema de saúde. Esta percepção dos trabalhadores traz a possibilidade de uma atuação holística, permitindo que o programa efetivamente se constitua em uma estratégia para reversão do modelo que atualmente temos como predominante.

Os trabalhadores também têm a percepção de que no seu trabalho "cuidam da saúde", para tanto necessitam de instrumentos e saberes específicos pois atuam na prevenção, planejamento de ações, orientação e melhora das condições da família. Desta forma, a humanização da assistência é discutida e "o cuidar se torna mais que um ato, uma atitude " (Boff, 1999).

Outros instrumentos e saberes foram identificados na realização da prática cotidiana do trabalho da equipe de Saúde da Família como: Ir em busca do usuário e o Vínculo. Ao ir em busca do usuário, muda-se a ótica de organização da assistência, passando a ser a família e seu espaço social o centro da atenção, possibilitando desta forma que as intervenções sejam mais adequadas a esta realidade. $O$ vínculo é tido como um dos pontos centrais do programa e 
necessário para a confiança dos usuários, que se caracterizaram como tendo uma grande necessidade de atenção não correspondida nos serviços já existentes.

Desta forma o vínculo é tido como um instrumento para o estimulo da autonomia e cidadania da comunidade, no entanto trabalhar com estas questões requer uma conscientização tanto dos profissionais como dos usuários.

Certamente, esta é uma aproximação inicial a este tema e outros aspectos merecem, em outro momento, maiores aprofundamentos de modo a identificar limites e possibilidades da assistência de enfermagem no Programa de Saúde da Familia.

ABSTRACT: This article is part of an integrated research project called The Organization of Primary Health Care ( a perspective for nursing practice). Its objective is to investigate the perception of nursing personnel concerning their practice in family-centered primary health care. This article presents a case study focuses on nursing personnel workers from the Family Health Program (PSF), in the city of Batatais. Data collection was done through semi-structured interviews with those professionals. Thematic analysis of the data was realized in which initial categorization was done with the help of the Ethnograph software. The topics identified in the workers' narratives were: comprehensiness, health care, bonding and active case-frading. These themes suggested that the work in family-centered care is difficult, therefore it leads to a more comprehensive health care pratice in which decision - making is shared withclientele.

KEYWORDS: primary health care, nursing practice, family health

RESUMEN: Este estudio se insiere en el proyecto integrado de investigación "La organización del trabajo en la atención primaria a la salud-una perspectiva para el trabajo de enfermeria". Tiene como objetivo estudiar la percepción de los trabajadores de enfermería cuanto a la configuración de la práctica de enfermeria en la atención primaria a la salud, dentro del ámbito de la atención a la salud de las familias. La investigación se configura como un estudio de caso y se centra en los trabajadores que actúan en el Programa de Salud de la Familia en el municipio de Batatais. Se realizó a través de una entrevista semiestructurada con los trabajadores de enfermeria del equipo del PSF. Se procedió al análisis temático del conjunto de datos y la categorización inicial se llevó a cabo con el auxilio del softwaree ETHNOGRAPH. Los temas identificados en las charlas de los trabajadores se referian a: la integralidad, a cuidar de la salud, a ir a buscar al usuario y el vínculo. Estos temas se encaminan hacia una percepción del trabajo en el PSF lleno de dificultades, pero al mismo tiempo lo conduce a una práctica volcada a la efectiva integralidad de la asistencia y de compartir mucho más las decisiones con la clientela.

PALABRAS CLAVE: Atención Primaria a la Salud, trabajo de enfermería, salud de la familia

\section{REFERÊNCIAS BIBLIOGRÁFICAS}

BOFF, Leonardo. Saber cuidar. Ética do humano - composiçăo pelo tema. Petrópolis: Ed. Vozes, 1999.

BRASIL. Constituição da República Federativa do Brasil. 1988. Săo Paulo: Ed. Revista dos Tribunais, 1989. 
BRASIL. Ministério da Saúde. Saúde da Familia: uma estratégia para reorientação do modelo assistencial. Brasilia, 1998

CAMPOS, Gastāo W.S. Subjetividades e Administraçāo de pessoal: consideraçōes sobre modos de gerenciar trabalho em equipe de saúde. In: MERHY, Emersom E. Agir em saúde - Um desafio para o público . São Paulo: Ed. Hucitec, 1997. Cap.7, p. 229-266.

DOMINGUEZ, Benito Narey Ramos. Programa de Saúde da Família: Como Fazer. São Paulo: Ed. Parma LTDA, 1998

IBAN / UNICEF. A saúde no municipio: organizaçāo e gestāo. 1991.

LÜDKE, Menga; ANDRÉ, Marli E.D.A. Abordagens qualitativas de pesquisa: a pesquisa etnográfica e o estudo de caso. In: LUDKE, Menga; ANDRÉ, Marli E.D.A. Pesquisa em educação: abordagem qualitativa. Săo Paulo: EPU, 1986, p.11-24.

MATUMOTO, S. O acolhimento: um estudo sobre seus componentes e sua produção em uma unidade da rede básica de serviços de saúde. Riberäo Preto, 1998. 225p. Dissertaçăo (Mestrado) - Escola de Enfermagem de Ribeirão Preto, USP.

MINAYO, Maria Cecilia S. O desafio do conhecimento - metodologia de pesquisa social (qualitativa) em saúde. 2.ed. São Paulo/Rio de Janeiro: Hucitec/ABRASCO, 1998.

SCHRAIBER, Lilia B.; GONÇALVES, Ricardo B.M. Necessidades de saúde e atenção primária. In SCHRAIBER, Lilia B.; NEMES, Maria Ines B.; GONÇALVES, Ricardo B.M. (orgs.) Saúde do adultoprogramas e ações na unidade básica. Săo Paulo: Ed. Hucitec, 1996, Cap.1, p.29-47. 